\title{
Effects of bavachin and its regulation of melanin synthesis in A375 cells
}

\author{
JING-HUA WANG ${ }^{1}$, YUAN-YUAN PEI ${ }^{2}$, HONG-DAN XU ${ }^{3}$, LI-JING LI $^{4}$, \\ YE-QIU WANG ${ }^{3}$, GUO-LIANG LIU ${ }^{3}$, YAN QU ${ }^{3}$ and NING ZHANG ${ }^{3}$ \\ ${ }^{1}$ College of Pharmacy, Mudanjiang Medical University, Mudanjiang, Heilongjiang 157011; \\ ${ }^{2}$ College of Pharmacy, Jiamusi University, Jiamusi, Heilongjiang 154007; ${ }^{3}$ College of Jiamusi, \\ Heilongjiang University of Chinese Medicine, Jiamusi, Heilongjiang $154007 ;{ }^{4}$ College of Pharmacy, \\ Changchun University of Chinese Medicine, Changchun, Jilin 130117, P.R. China
}

Received December 11, 2015; Accepted February 9, 2016

DOI: $10.3892 /$ br.2016.688

\begin{abstract}
The aim of the present study was to investigate the effect of bavachin treatment on A375 cells and the regulation of melanin synthesis. The cultured A375 cells in vitro were treated with bavachin; and the effect of bavachin on cell activity, tyrosinase (TYR) activity and melanin synthesis were respectively tested by the MTT assay, L-dopa oxidation assay and the $\mathrm{NaOH}$ lysis assay. The expression levels of TYR and c-Jun N-terminal kinases (JNK) proteins were tested by western blot analysis. The expression levels of $T Y R$, tyrosinase-related protein-1 (TRP-1), TRP-2, extracellular signal-regulated kinase 1 (ERK1), ERK2 and JNK2 mRNA were tested by the reverse transcription-polymerase chain reaction assay. Simultaneously, the effect of estrogen receptor inhibitor (ICI182780) and ERK pathway inhibitor (U0126) was also tested on A375 cells following bavachin. The safe dose of bavachin significantly inhibited melanin synthesis and TYR activity. Bavachin $(10 \mu \mathrm{mol} / \mathrm{l})$ inhibited the expression of TYR and JNK proteins, and the expression of TYR, TRP-1, TRP-2, ERK1, ERK2 and JNK2 mRNA in A375 cells. ICI182780 and U0126 could significantly reverse the bavachin treatment on the protein expression levels and the mRNA expression of TYR, TRP-1, TRP-2, ERK1, ERK2 and JNK2. In conclusion, bavachin inhibited the synthesis of melanin on A375 cells by inhibiting the protein and mRNA expression of TYR, TRP-1, TRP-2, ERK1, ERK2 and JNK2.
\end{abstract}

\section{Introduction}

Psoralea coryfolia is a traditional tonifying drug, which can tonify renal function and is antidiarrheal. A previous study

Correspondence to: Dr Ning Zhang, College of Jiamusi, Heilongjiang University of Chinese Medicine, 39 Guanghua Road, Jiamusi, Heilongjiang 154007, P.R. China

E-mail: zhangning_1@163.com

Key words: bavachin, estrogen receptor-mitogen-activated protein kinase, A375 cells, melanin illustrated that Psoralea coryfolia has estrogen-like effects (1). For adult ovariectomized female-mice, Psoralea coryfolia could not only increase keratinization of vaginal epithelial cells and enhance the weight of the uterus, but it also has an influence on their estrous cycles, which demonstrate the estrogen effects of Psoralea coryfolia (2). Bavachin is one of the classic flavonoid phytoestrogens extracted from Psoralea coryfolia (3-5). Phytoestrogens are one of the selective estrogen receptor (ER) modulators extracted from plants with a structure similar to estrogen, which may have an important role in the treatment of skin disease as a substitute of estrogen, due to its estrogen-like effects but mild estrogen-like side effects (6). Previously, certain studies have shown that Psoralea coryfolia and certain phytoestrogens extracted from Psoralea coryfolia that exhibit estrogen-like effects were closely connected with melanin synthesis. Psoralea coryfolia combined with psoralen combined with ultraviolet A (UVA) treatment could increase the activity of melanocytes, and reduce the degeneration of melanocytes and keratinocytes (7). Bakuchiol, bavachin and isobavachalcone can inhibit melanin synthesis in B16 mouse melanoma cells (8). Phytoestrogen can regulate melanin synthesis of melanocytes through the mitogen-activated protein kinase (MAPK) signaling pathway initiated by binding of phytoestrogen to the ER. Thus, bavachin may regulate melanin synthesis of A375 cells through the ER-MAPK signaling pathway.

\section{Materials and methods}

Cells and reagents. Human A375 cells (Cell Center of Chinese Academy of Sciences, Beijing, China), MTT (Sigma-Aldrich, St. Louis, MO, USA), Dulbecco's modified Eagle's medium (DMEM; Hyclone, Thermo Fisher Scientific, Inc., Waltham, MA, USA), cell lysis buffer for Western blotting and immunoprecipitation (Beyotime Institute of Biotechnology, Shanghai, China), goat anti-mouse immunoglobulin $\mathrm{G}$ conjugated with horseradish peroxidase (cat. no. BA1050; Wuhan Boster Golden Bridge Biological Technology Co., Ltd., Wuhai, China), mouse anti- $\beta$-actin monoclonal antibody (cat. no. TA-09; Beijing Zhongshan Jinqiao Biotechnology Co., Ltd., Beijing, China), mouse anti-tyrosinase (TYR) monoclonal antibody 
(cat. no. sc-20035; Santa Cruz Biotechnology, Inc., Santa Cruz, CA, USA), mouse anti-JNK monoclonal antibody (Santa Cruz Biotechnology, Inc.), primer (Sangon Biotech Co., Ltd., Shanghai, China) and TRIzol reagent (Gibco, Thermo Fisher Scientific, Inc.) were purchased.

Instruments. A TCL6G-C table-top high-speed refrigerated centrifuge (Anting, Shanghai, China), MK3 Enzyme microplate reader (Redian, Shanghai, China), DYCZ-40B transfer electrophoresis cell (Liuyi, Beijing, China), Professional polymerase chain reaction (PCR) Amplification Instrument (Biometra, Gottingen, Germany), SmartChemi ${ }^{\mathrm{TM}}$ Image Analysis system (Beijing Sage Creation Science Co., Ltd., Beijing, China) and Nano-100 Spectrophotometry (Aosheng, Hangzhou, China) were the instruments used.

Drugs. Bavachin with a purity $>98 \%$ (20130829; Baoji Herbest Bio-Tech Co., Ltd., Baoji, China), estradiol with a purity $>98 \%$ (L750N46; Bailingwei, Beijing, China), ICI182780 (20A/129473; Tocris Bioscience, Bristol, UK) and U0126 (S110202; Selleck, Houston, TX, USA) were used for the treatments of the cells.

Drug solution preparation. Estradiol was precisely weighed (5.5 $\mathrm{mg})$, dissolved with $4 \mathrm{ml}$ anhydrous alcohol, and DMEM complete medium was added to a total volume of 1 liter. A stock solution with a concentration of $20 \mu \mathrm{mol} / 1$ was prepared and diluted to $10^{-3} \mu \mathrm{mol} / \mathrm{l}$ when used. Bavachin was weighed precisely $(6.49 \mathrm{mg})$ and dissolved with DMEM complete medium to a total volume of $100 \mathrm{ml}$. The solution was prepared with an initial concentration of $200 \mu \mathrm{mol} / 1$, and diluted to $10 \mu \mathrm{mol} / \mathrm{l}$ when used. ICI1 82780 was weighed precisely $(5 \mathrm{mg})$, dissolved with $1 \%$ dimethyl sulphoxide (DMSO) and DMEM complete medium was added to prepare the solution with an initial concentration of $200 \mu \mathrm{mol} / 1$. This solution was diluted to $1 \mu \mathrm{mol} / 1$ when used. U0126 was weighed precisely $(8.53 \mathrm{mg})$, dissolved with $1 \%$ DMSO and DMEM complete medium was added to prepare the solution with an initial concentration of $400 \mu \mathrm{mol} / 1$. The solution was diluted to $10 \mu \mathrm{mol} / 1$ when used. All the solutions were filtered and sterilized by $0.22-\mu \mathrm{m}$ filter membrane, and stored at $-20^{\circ} \mathrm{C}$.

Cell grouping and culture. A375 cells in the logarithmic growth phase were prepared and subsequently digested, centrifuged and resuspended. The cells were transferred to 96 -well plates (200 $\mu 1$ medium with 4,500 cells per well) or 6-well plates ( $2 \mathrm{ml}$ medium with $24 \times 10^{4}$ cells per well), cultured in $5 \% \mathrm{CO}_{2}$ at $37^{\circ} \mathrm{C}$ for $24 \mathrm{~h}$, the medium was discarded and the cells were divided into different groups according to the drug treatments. For the control group, medium without drugs was added; for the estradiol group, estradiol solution with a concentration of $10^{-3} \mu \mathrm{mol} / 1$ was added; for the bavachin group, $10 \mu \mathrm{mol} / 1$ bavachin solution was added; for the bavachin + ICI182780 group, $1 \mu \mathrm{mol} / 1$ ICI182780 solution was added, and bavachin stock solution was added $1 \mathrm{~h}$ later, with a bavachin concentration that was identical to the bavachin group. For the bavachin + U0126 group, $10 \mu \mathrm{mol} / 1 \mathrm{U} 0126$ solution was added, and 20 min later the bavachin stock solution was added to make a concentration of bavachin that was identical to the bavachin group. All the cell groups were cultured for a further
$48 \mathrm{~h}$. There were 6 wells for duplicate treatments in the 96-well plates, and 4 wells for duplicate treatments in 6-well plates.

\section{Detection index}

Cell activity. MTT solution ( $20 \mu \mathrm{l})$ was added to each well of the 96 -well plates, the cells were cultured for $4 \mathrm{~h}$, the solution was discarded, and the purple crystal was dissolved in the wells with $150 \mu \mathrm{l} \mathrm{DMSO}$ solution, agitated in a $37^{\circ} \mathrm{C}$ incubator shaker for $10 \mathrm{~min}$, and the optical density (OD) was measured at $490 \mathrm{~nm}$ by the microplate reader.

Melanin content. The cultured solution in the 6-well plates was discarded, the cells were washed with phosphate-buffered saline (PBS) twice and were digested with $1 \mathrm{ml} 0.25 \%$ pancreatin for $1 \mathrm{~min}$. DMEM total medium was added $(1 \mathrm{ml})$ to stop the digestion, the cell suspension was collected in a $15-\mathrm{ml}$ centrifuge tube, the sample underwent centrifugation at a speed of 2,000 $\mathrm{x}$ g for $5 \mathrm{~min}$ and the supernatant was discarded. Following this, $100 \mu \mathrm{l}$ of $1 \mathrm{~mol} / \mathrm{l} \mathrm{NaOH}$ solution was added, mixed and placed in a centrifuge tube in water at $37^{\circ} \mathrm{C}$ for $1 \mathrm{~h}$. Subsequently, $400 \mu \mathrm{l}$ double-distilled water was added, the sample was mixed, and a $100 \mu \mathrm{l}$ solution was removed from each centrifuge tube to 96-well plates, and the OD was measured at $490 \mathrm{~nm}$ by the microplate reader.

TYR activity. The culture solution in the 96-well plates was discarded, the cells were washed with PBS twice, $100 \mu 1$ $1 \%$ Triton-X-100 was added in each well, and the cell samples were rapidly frozen at $-80^{\circ} \mathrm{C}$ for $30 \mathrm{~min}$. Following this, $50 \mu \mathrm{l}$ PBS [with $0.2 \%$ L-dopa (pH 6.8)] was added to each well, the cells were cultured at $37^{\circ} \mathrm{C}$ for $3 \mathrm{~h}$, and the $\mathrm{OD}$ at a wavelength of $490 \mathrm{~nm}$ was detected by the microplate reader.

Western blot analysis of TYR and c-Jun N-terminal kinases (JNK) protein expression levels. The total protein of each group in the 6-well plates was collected and detected. Polyacrylamide gel electrophoresis was used to separate the protein, which was transferred to a polyvinylidene difluoride membrane, blocked with non-specific binding using $5 \%$ non-fat milk for $2 \mathrm{~h}$, following which the samples were incubated with primary antibodies (1:300) overnight at $4^{\circ} \mathrm{C}$. Following this, the samples were incubated with secondary antibodies in a separate process, and colored with electrochemiluminescence. Images of each sample were captured and the gray value of each band was analyzed. The amount of target protein is shown by the ratio of its gray value to the internal reference.

Analysis of TYR, tyrosinase-related protein-1 (TRP-1), TRP-2, extracellular signal-regulated kinase 1 (ERK1), ERK2 and JNK2 $\mathrm{mRNA}$ expression levels by reverse transcription $(R T)$-PCR. The total cells in the 6-well plates of each group were collected. The total RNA was extracted according to the manufacturer's protocol for TRIzol. For RT, $3 \mu \mathrm{g}$ RNA was collected from each group. The reaction conditions were as follows: Sample was incubated at $25^{\circ} \mathrm{C}$ for $10 \mathrm{~min}$, at $42^{\circ} \mathrm{C}$ for $60 \mathrm{~min}$ and at $70^{\circ} \mathrm{C}$ for $10 \mathrm{~min}$, before terminating the reaction and obtaining the cDNA. Primer sequences were designed and composed by Sangon Biotech Co., Ltd. The primer sequences, with the reference gene $\beta$-actin, are shown in Table I. Amplification conditions were as follows: Initial denaturation at $94^{\circ} \mathrm{C}$ for $2 \mathrm{~min}$, denaturation for $30 \mathrm{sec}$ at $94^{\circ} \mathrm{C}$, annealing for $40 \mathrm{sec}\left(T Y R\right.$ at $60^{\circ} \mathrm{C}, T R P-1$ at $58^{\circ} \mathrm{C}, T Y P-2$ at $58^{\circ} \mathrm{C}, E R K 1$ at $58^{\circ} \mathrm{C}, E R K 2$ at $55^{\circ} \mathrm{C}, J N K 2$ at $55^{\circ} \mathrm{C}$ and $\beta$-actin at $55^{\circ} \mathrm{C}$, respectively), and the extension was for $40 \mathrm{sec}$ at $70^{\circ} \mathrm{C}$. 
Table I. Polymerase chain reaction primer sequences.

\begin{tabular}{llll}
\hline $\begin{array}{l}\text { Primer } \\
\text { name }\end{array}$ & \multicolumn{1}{c}{$\begin{array}{c}\text { Upstream } \\
\text { primer }\end{array}$} & \multicolumn{1}{c}{$\begin{array}{c}\text { Downstream } \\
\text { primer }\end{array}$} & $\begin{array}{c}\text { Amplified fragment, } \\
\text { base pairs }\end{array}$ \\
\hline$T Y R$ & 5'TCACGGCTCTGTTGAATGTCT3' & 5'CTGAAGTTGGGCGAGATGAT3' & 300 \\
$T R Y$ & 5'ACATCATTCCCTCACCAAAGAC3' & 5'AGAAGTCCGAAAGCCAAGTAAA3' & 303 \\
$T R P-2$ & 5'GTTCCTTTCTTCCCTCCAGTG3' & 5'TTCCTTTATTGTCAGCGTCAGA3' & 300 \\
$E R K 1$ & 5'GGGAGGTGGAGATGGTGAAG3' & 5'AGCAGGTTGGAGGGCTTTAGAT3' & 441 \\
$E R K 2$ & 5'ACCCACACAAGAGGATTGAAGT3' & 5'AAAAGCCACAACTACCAGAAAC3' & 353 \\
$J N K 2$ & 5'CCTTCTTTACCAGATGCTTTGTG3' & 5'ATACGGTCAGTGCCTTGGAATA3' & 303 \\
$\beta$-actin & 5'CGTGGACATCCGCAAAGAC3' & 5'AAGAAAGGGTGTAACGCAACTA3' & 302 \\
\hline
\end{tabular}

$T Y R$, tyrosinase; TRP, tyrosinase-related protein; ERK, extracellular signal-regulated kinase; JNK, c-Jun N-terminal kinases.

Table II. Effects of bavachin on A375 cells activity.

\begin{tabular}{lcc}
\hline Group $(\mu \mathrm{mol} / \mathrm{l})$ & OD & Cell proliferation rate, $\%$ \\
\hline Control $(0)$ & $0.466 \pm 0.029$ & 100.00 \\
Estradiol $\left(10^{-3}\right)$ & $0.564 \pm 0.029^{\mathrm{a}}$ & $121.03^{\mathrm{a}}$ \\
Bavachin $(10)$ & $0.436 \pm 0.020$ & 93.56
\end{tabular}

Compared with the control group, ${ }^{\text {a }}<0.01$. Data are mean \pm standard deviation and $\mathrm{n}=6$. OD, optical density at $490 \mathrm{~nm}$.

Table III. Effects of bavachin on melanin synthesis in A375 cells.

\begin{tabular}{lcc}
\hline Group $(\mu \mathrm{mol} / \mathrm{l})$ & OD & $\mathrm{OD}_{\text {treatment group }} / \mathrm{OD}_{\text {control group }} \%$ \\
\hline Control (0) & $0.138 \pm 0.014$ & 100.00 \\
Estradiol $\left(10^{-3}\right)$ & $0.168 \pm 0.009^{\mathrm{a}}$ & $121.74^{\mathrm{a}}$ \\
Bavachin (10) & $0.076 \pm 0.016^{\mathrm{a}}$ & $55.07^{\mathrm{a}}$ \\
Bavachin (10)+ & $0.114 \pm 0.004^{\mathrm{a}, \mathrm{b}}$ & $82.61^{\mathrm{a}, \mathrm{b}}$ \\
ICI182780 (1) & \\
Bavachin (10) $+0.109 \pm 0.010^{\mathrm{a}, \mathrm{b}}$ & $78.99^{\mathrm{a}, \mathrm{b}}$ \\
U0126 (10) &
\end{tabular}

Compared with the control group, ${ }^{\mathrm{a}} \mathrm{P}<0.01$; compared with the bavachin group, ${ }^{\mathrm{b}} \mathrm{P}<0.01$. Data are mean \pm standard deviation and $\mathrm{n}=4$. OD, optical density at $490 \mathrm{~nm}$.

A total of 35 PCR cycles were used for amplification of the samples. The PCR amplification products $(5 \mu \mathrm{l})$ were mixed with $1 \mu \mathrm{l}$ of $6 \mathrm{X}$ DNA loading buffer. The PCR products were fractionated by $1.5 \%$ agarose gel electrophoresis at a constant voltage of $120 \mathrm{~V}$ for $30 \mathrm{~min}$. The results were detected using a gel imaging system, and were analyzed with gel-pro analysis software (Media Cybernetics, Inc., Rockville, MD, USA). The mRNA levels of each group were calculated as the relative expression ratio to that of $\beta$-actin $(T Y R / \beta$-actin, $T R P$ - $1 / \beta$-actin, $T R P$ - $2 / \beta$-actin, ERK1/ $\beta$-actin, ERK2/ $\beta$-actin and $J N K 2 / \beta$-actin).

Statistical analysis. The obtained data are expressed as mean \pm standard deviation, statistically analyzed by one-way
Table IV. Effects of bavachin on TYR activity of A375 cells.

\begin{tabular}{lcc}
\hline Group $(\mu \mathrm{mol} / \mathrm{l})$ & $\mathrm{OD}$ & $\mathrm{OD}_{\text {treatment group }} / \mathrm{OD}_{\text {control group }}, \%$ \\
\hline Control (0) & $0.087 \pm 0.006$ & 100.00 \\
Estradiol $\left(10^{-3}\right)$ & $0.107 \pm 0.004^{\mathrm{a}}$ & $122.99^{\mathrm{a}}$ \\
Bavachin $(10)$ & $0.063 \pm 0.004^{\mathrm{a}}$ & $72.41^{\mathrm{a}}$ \\
Bavachin $(10)+$ & $0.080 \pm 0.004^{\mathrm{b}, \mathrm{c}}$ & $91.95^{\mathrm{b}, \mathrm{c}}$ \\
ICI182780 (1) & \\
Bavachin (10) + & $0.077 \pm 0.009^{\mathrm{a}, \mathrm{c}}$ & $88.51^{\mathrm{a}, \mathrm{c}}$ \\
U0126 (10) & \\
\hline
\end{tabular}

Compared with the control group, ${ }^{b} \mathrm{P}<0.05$, ${ }^{\mathrm{a}} \mathrm{P}<0.01$; compared with the bavachin group, ${ }^{\mathrm{C}} \mathrm{P}<0.01$. Data are mean \pm standard deviation and $\mathrm{n}=6$. TYR, tyrosinase; OD, optical density at $490 \mathrm{~nm}$.

analysis of variance using the SPSS software (version 18.0; SPSS, Inc., Chicago, IL, USA). A 2:2 comparison was conducted by least significant difference. $\mathrm{P}<0.05$ was considered to indicate a statistically significant difference.

\section{Results}

Effect on cell activity. The effects of bavachin on A375 cells activity are shown in Table II. Treatment with $10 \mu \mathrm{mol} / 1$ bavachin had no significant effect on A375 cells activity when compared to the control group. Therefore, it could be used in the follow-up experiments.

Effects of bavachin on melanin synthesis of the A375 cells. The results for the effect of bavachin treatment on melanin synthesis in A375 cells are shown in Table III. Bavachin significantly inhibited melanin synthesis, which was $55.07 \%$ of the control group $(\mathrm{P}<0.01)$. ICI182780 and U0126 could reverse the melanin decline induced by bavachin, and the differences were significant when compared with the bavachin group $(\mathrm{P}<0.01)$.

Effects of bavachin on TYR activity of A375 cells. The results for the effects of bavachin on TYR activity are shown in Table IV. Bavachin significantly inhibited TYR activity, 
Table V. Expression levels of TYR and JNK proteins in the different groups.

\begin{tabular}{lll}
\hline Group $(\mu \mathrm{mol} / \mathrm{l})$ & TYR/ $\beta$-actin & JNK $/ \beta$-actin \\
\hline Control $(0)$ & $0.558 \pm 0.018$ & $0.477 \pm 0.018$ \\
Estradiol $\left(10^{-3}\right)$ & $0.693 \pm 0.030^{\mathrm{a}}$ & $0.583 \pm 0.011^{\mathrm{a}}$ \\
Bavachin $(10)$ & $0.358 \pm 0.032^{\mathrm{a}}$ & $0.221 \pm 0.003^{\mathrm{a}}$ \\
Bavachin $(10)+$ & $0.477 \pm 0.005^{\mathrm{a}, \mathrm{b}}$ & $0.332 \pm 0.029^{\mathrm{a}, \mathrm{b}}$ \\
ICI182780 (1) & &
\end{tabular}

Compared with the control group, ${ }^{\text {a }}<0.01$; compared with the bavachin group, ${ }^{b} \mathrm{P}<0.01$. Data are mean \pm standard deviation and $\mathrm{n}=4$. TYR, tyrosinase; JNK, c-Jun N-terminal kinases.

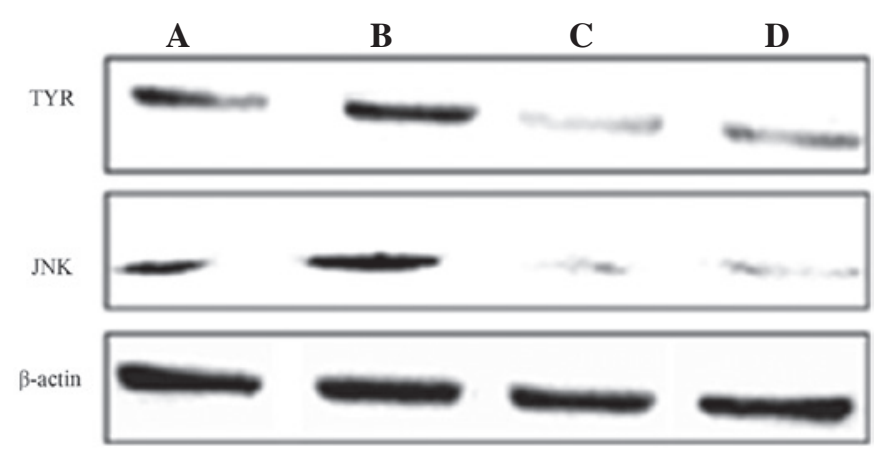

Figure 1. Expression levels of TYR and JNK proteins in the different groups. (A) Control; (B) estradiol; (C) bavachin; and (D) bavachin + ICI182780 groups.

which was $72.41 \%$ of the control group ( $\mathrm{P}<0.01)$. ICI182780 and U0126 reversed the decline of TYR activity induced by bavachin, and the differences were significant compared with the bavachin group $(\mathrm{P}<0.01)$.

Effects of bavachin on the expression levels of the TYR and JNK proteins. The effects of bavachin treatment on TYR and JNK proteins are shown in Table V and Fig. 1. Bavachin significantly inhibited the expression levels of the TYR and
JNK proteins when compared with the control group $(\mathrm{P}<0.01)$. ICI182780 reversed the decline of the TYR protein and the JNK protein as induced by bavachin, and the differences were significant compared to the bavachin group $(\mathrm{P}<0.01)$.

\section{$R T$ - $P C R$ results}

Effects of bavachin and ICII82780 on the expression levels of the TYR, TRP-1, TRP-2, ERK1, ERK2 and JNK2 mRNA in the A375 cells. The effects of bavachin and ICI182780 are shown in Table VI and Fig. 2. Bavachin significantly inhibited the expression levels of TYR, TRP-1, TRP-2, ERK1, ERK2 and $J N K 2$ mRNA when compared with the control group $(\mathrm{P}<0.01)$. ICI182780 reversed the decline of the TYR, TRP-1, TRP-2, $E R K 1, E R K 2$ and $J N K 2 \mathrm{mRNA}$ as induced by bavachin, and the differences were significant when comparing with the bavachin group $(\mathrm{P}<0.05$ or $\mathrm{P}<0.01)$.

Effects of bavachin and U0126 on expression of TYR, TRP-1 and TRP-2 mRNA in A375 cells. The results of the effects of bavachin and U0126 are shown in Table VII and Fig. 3. Bavachin significantly inhibited the expression of TYR, TRP-1 and TRP-2 mRNA, as compared with the control group $(\mathrm{P}<0.01)$. U0126 reversed the decline of the TYR, TRP-1 and $T R P-2$ mRNA induced by bavachin, and the differences were significant when compared with the bavachin group $(\mathrm{P}<0.01$ or $\mathrm{P}<0.05)$.

\section{Discussion}

Melanin is produced in the melanosome of melanocytes regulated by TYR, which is the main rate-limiting enzyme of this process. The TYR genes mainly includes $T Y R, T R P-1$ and $T R P-2$ (9-11). Estrogen, as an extracellular stimuli, can bind to ER, which also exists in melanocytes, and subsequently activate the extracellular signal transduction pathway directly or indirectly, which can induce a nongenomic effect. The ER-related regulation is well-connected with the MAPK signaling pathway, which is a common pathway of physiological reactions responding to extracellular stimuli. MAPK belongs to the serine-threonine kinases. A previous study also demonstrated that the MAPK pathway is involved in the regulation of melanin synthesis (12). The MAPK family mainly consists of ERK1/2, JNK1/2 and p38 MAPK (13).

Table VI. Polymerase chain reaction analysis of the TYR, TRP-1,TRP-2, ERK1,ERK2 and JNK2 mRNA expression levels in the different groups.

\begin{tabular}{lcccc}
\hline mRNA & $\begin{array}{c}\text { Control group } \\
(0 \mu \mathrm{mol} / \mathrm{l})\end{array}$ & $\begin{array}{c}\text { Estradiol group } \\
\left(10^{-3} \mu \mathrm{mol} / \mathrm{l}\right)\end{array}$ & $\begin{array}{c}\text { Bavachin group } \\
(10 \mu \mathrm{mol} / \mathrm{l})\end{array}$ & $\begin{array}{c}\text { Bavachin }(10 \mu \mathrm{mol} / \mathrm{l})+ \\
\text { ICI182780 }(1 \mu \mathrm{mol} / \mathrm{l})\end{array}$ \\
\hline$T Y R / \beta$-actin & $0.583 \pm 0.006$ & $0.691 \pm 0.017^{\mathrm{a}}$ & $0.332 \pm 0.038^{\mathrm{a}}$ & $0.470 \pm 0.047^{\mathrm{a}, \mathrm{b}}$ \\
$T R P-1 / \beta$-actin & $0.424 \pm 0.022$ & $0.561 \pm 0.012^{\mathrm{a}}$ & $0.251 \pm 0.029^{\mathrm{a}}$ & $0.357 \pm 0.013^{\mathrm{a}, \mathrm{b}}$ \\
$T R P-2 / \beta$-actin & $0.427 \pm 0.010$ & $0.532 \pm 0.014^{\mathrm{a}}$ & $0.289 \pm 0.022^{\mathrm{a}}$ & $0.346 \pm 0.036^{\mathrm{a}, \mathrm{c}}$ \\
$E R K 1 / \beta$-actin & $0.461 \pm 0.038$ & $0.561 \pm 0.021^{\mathrm{a}}$ & $0.299 \pm 0.009^{\mathrm{a}}$ & $0.357 \pm 0.047^{\mathrm{a}, \mathrm{b}}$ \\
$E R K 2 / \beta$-actin & $0.507 \pm 0.019$ & $0.620 \pm 0.031^{\mathrm{a}}$ & $0.320 \pm 0.020^{\mathrm{a}}$ & $0.417 \pm 0.027^{\mathrm{a}, \mathrm{c}}$ \\
$J N K 2 / \beta$-actin & $0.491 \pm 0.013$ & $0.591 \pm 0.012^{\mathrm{a}}$ & $0.276 \pm 0.040^{\mathrm{a}}$ & $0.357 \pm 0.033^{\mathrm{a}, \mathrm{c}}$ \\
\hline
\end{tabular}

Compared with the control group, ${ }^{\mathrm{a}} \mathrm{P}<0.01$; compared with the bavachin group, ${ }^{\mathrm{b}} \mathrm{P}<0.05,{ }^{\mathrm{c}} \mathrm{P}<0.01$. Data are mean \pm standard deviation and $\mathrm{n}=4$. $T Y R$, tyrosinase; TRP, tyrosinase-related protein; ERK, extracellular signal-regulated kinase; JNK, c-Jun N-terminal kinases. 
Table VII. Polymerase chain reaction analysis of TYR, TRP-1 and TRP-2 mRNA expression levels in the different groups.

\begin{tabular}{lcccc}
\hline mRNA & $\begin{array}{c}\text { Control group } \\
(0 \mu \mathrm{mol} / \mathrm{l})\end{array}$ & $\begin{array}{c}\text { Estradiol group } \\
\left(10^{-3} \mu \mathrm{mol} / \mathrm{l}\right)\end{array}$ & $\begin{array}{c}\text { Bavachin group } \\
(10 \mu \mathrm{mol} / \mathrm{l})\end{array}$ & $\begin{array}{c}\text { Bavachin }(10 \mu \mathrm{mol} / \mathrm{l})+ \\
\mathrm{U} 0126(1 \mu \mathrm{mol} / \mathrm{l})\end{array}$ \\
\hline TYR/ $\beta$-actin & $0.564 \pm 0.016$ & $0.676 \pm 0.011^{\mathrm{a}}$ & $0.368 \pm 0.034^{\mathrm{a}}$ & $0.413 \pm 0.037^{\mathrm{a}, \mathrm{b}}$ \\
$T R P-1 / \beta$-actin & $0.458 \pm 0.010$ & $0.547 \pm 0.022^{\mathrm{a}}$ & $0.291 \pm 0.009^{\mathrm{a}}$ & $0.392 \pm 0.015^{\mathrm{a}, \mathrm{c}}$ \\
$T R P-2 / \beta$-actin & $0.411 \pm 0.007$ & $0.549 \pm 0.016^{\mathrm{a}}$ & $0.265 \pm 0.033^{\mathrm{a}}$ & $0.348 \pm 0.008^{\mathrm{a}, \mathrm{c}}$ \\
\hline
\end{tabular}

Compared with the control group, ${ }^{\mathrm{a}} \mathrm{P}<0.01$; compared with the bavachin group, ${ }^{\mathrm{b}} \mathrm{P}<0.05,{ }^{\mathrm{c}} \mathrm{P}<0.01$. Data are mean \pm standard deviation and $\mathrm{n}=4$. $T Y R$, tyrosinase; TRP, tyrosinase-related protein.
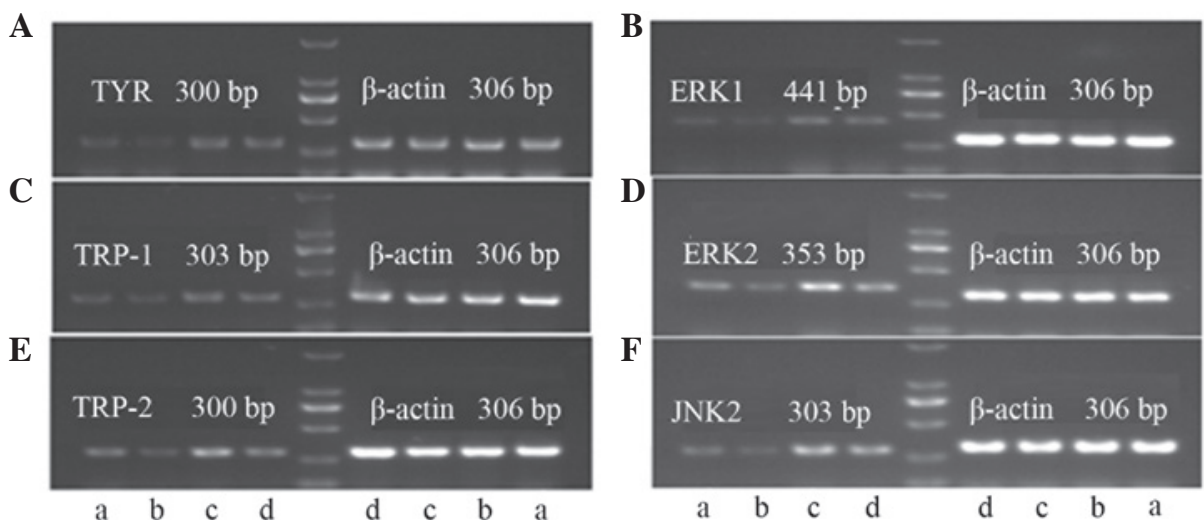

Figure 2. Polymerase chain reaction analysis of (A) TYR, (B) ERK1, (C) TRP-1, (D) ERK2, (E) TRP-2 and (F) JNK2 mRNA expression levels in the A375 cells in the different groups. (a) Bavachin + ICI182780; (b) bavachin; (c) estradiol; and (d) control groups. TYR, tyrosinase; TRP, tyrosinase-related protein; ERK, extracellular signal-regulated kinase; JNK, c-Jun N-terminal kinases; bp, base pairs.

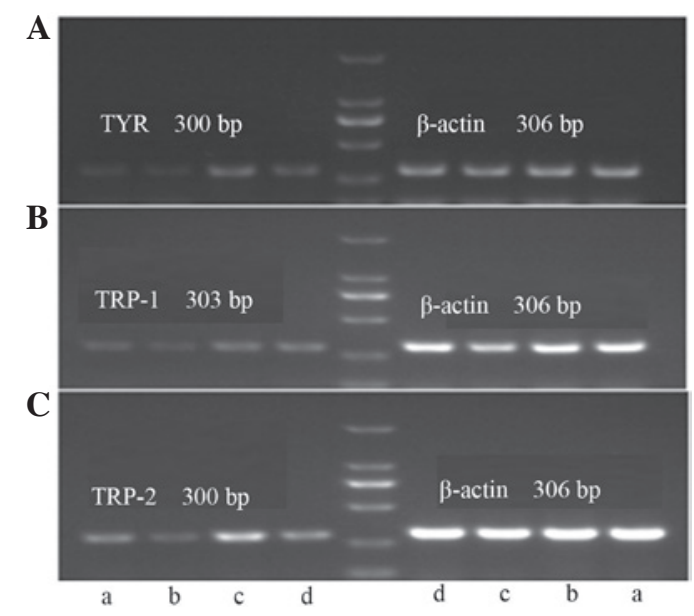

Figure 3. Polymerase chain reaction analysis of (A) $T Y R$, (B) $T R P-1$ and (C) TRP-2 mRNA expression in the A375 cells in different groups. (a) Wogonin + U0126; (b) wogonin; (c) estradiol; (d) control groups. TYR, tyrosinase; TRP, tyrosinase-related protein; bp, base pairs.

The studies have shown that activation of MAPK signaling may be an important pathway involved in melanoma transformation. Inhibition of MAPK signaling may be useful in the prevention and treatment of melanoma (14). The study by Yanase et al (15) demonstrated that the expression of TYR mRNA and protein increase phosphorylation, and activity of ERK1/2 elevated following UVA irradiation. However, treatment with a tyrosine kinase receptor inhibitor reduced ERK1/2 activation following UVA-irradiation, which suggested that UVA irradiation-induced melanogenesis is associated with the activation of ERK1/2 by upstream signals that originate from reactive oxygen species or from activated tyrosine kinase receptors (15). Hata et al (16) reported that activation of the p38 MAPK signaling pathway induced differentiation of B16 melanoma cells. In a previous study, Ali et al (17) indicated that phytoestrogen extracted from Psoralea coryfolia is connected with melanin synthesis, the lyophilized extracts of Psoralea corylifolia seeds and pure psoralen induced melanin dispersal effects; however, the underlying regulation mechanism remains to be elucidated.

In the present study, the safe dose of bavachin could significantly inhibit melanin synthesis and TYR activity in A375 cells, which could be reversed by ICI182780 and U0126. This suggested that bavachin inhibits melanin synthesis by decreasing TYR activity, which was achieved by the ER-ERK pathway. Western blot analysis shows that bavachin could significantly inhibit the expression of TYR and JNK protein in the A375 cells, which could be reversed by ICI182780. This indicates that lessening the expression of TYR and JNK protein is connected with regulation of melanin synthesis. RT-PCR showed that bavachin could significantly inhibit the expression of TYR, TRP-1, TRP-2, $E R K 1, E R K 2$ and $J N K 2$ mRNA, which may be involved in the regulation of melanin synthesis. Notably, bavachin inhibited the synthesis of melanin on A375 cells by inhibiting expression of TYR, TRP-1, TRP-2, ERK1, ERK2 and JNK2 protein and mRNA. 


\section{Acknowledgements}

The study was sponsorted by grants from the National Natural Science Foundation of China (General Program; no. 81274035); Postdoctoral Research Starting Capital of Heilongjiang Province (no. LBH-Q13162); and the Excellent Innovation Talents of Heilongjiang University of Chinese Medicine.

\section{References}

1. Xu Y, Zhang ZJ, Geng F, Su SB, White KN, Bligh SW, Branford-White CJ and Wang ZT: Treatment with Qing'E, a kidney-invigorating Chinese herbal formula, antagonizes the estrogen decline in ovariectomized mice. Rejuvenation Res 13: 479-488, 2010.

2. Research Office of family planning, stitute of Chinese Traditional Medicine: Academy of Traditional Chinese Medicine. Research Data Traditional Chinese Medicine of Meijing 1: 16-18, 1979.

3. Lim SH, Ha TY, Ahn J and Kim S: Estrogenic activities of Psoralea corylifolia L. seed extracts and main constituents. Phytomedicine 18: 425-430, 2011.

4. Lim SH, Ha TY, Kim SR, Ahn J, Park HJ and Kim S: Ethanol extract of Psoralea corylifolia L. and its main constituent, bakuchiol, reduce bone loss in ovariectomised Sprague-Dawley rats. Br J Nutr 101: 1031-1039, 2009.

5. Xin D, Wang H, Yang J, Su YF, Fan GW, Wang YF, Zhu Y and Gao XM: Phytoestrogens from Psoralea corylifolia reveal estrogen receptor-subtype selectivity. Phytomedicine 17: 126-131, 2010.

6. Shelly W, Draper MW, Krishnan V, Wong M and Jaffe RB: Selective estrogen receptor modulators: An update on recent clinical findings. Obstet Gynecol Surv 63: 163-181, 2008.

7. Anbar TS, El-Sawy AE, Attia SK, Barakat MT, Moftah NH, El-Ammawy TS, Abdel-Rahman AT and El-Tonsy MH: Effect of PUVA therapy on melanocytes and keratinocytes in non-segmental vitiligo: Histopathological, immuno-histochemical and ultrastructural study. Photodermatol Photoimmunol Photomed 28: 17-25, 2012.
8. Ohno O, Watabe T, Nakamura K, Kawagoshi M, Uotsu N, Chiba T, Yamada M, Yamaguchi K, Yamada K, Miyamoto K and Uemura D: Inhibitory effects of bakuchiol, bavachin, and isobavachalcone isolated from Piper longum on melanin production in B16 mouse melanoma cells. Biosci Biotechnol Biochem 74: 1504-1506, 2010.

9. Hashimoto Y, Ito Y, Kato T, Motokawa T, Katagiri T and Itoh M: Expression profiles of melanogenesis-related genes and proteins in acquired melanocytic nevus. J Cutan Pathol 33: 207-215, 2006.

10. Lu F, Yan D, Zhou X, Hu DN and Qu J: Expression of melanin-related genes in cultured adult human retinal pigment epithelium and uveal melanoma cells. Mol Vis 13: 2066-2072, 2007.

11. Fang D, Kute T and Setaluri V: Regulation of tyrosinase-related protein-2 (TYRP2) in human melanocytes: Relationship to growth and morphology. Pigment Cell Res 14: 132-139, 2001.

12. Jiang ZQ: The Mechanism of Active Componets of Two Chinese Traditional Medicines on Melanogenesis (unpublished $\mathrm{PhD}$ thesis). Huazhong University of Science and Technology, $1114360302971160,2009$.

13. Cohen P: The search for physiological substrates of MAP and SAP kinases in mammalian cells. Trends Cell Biol 7: 353-361, 1997.

14. Govindarajan B, Bai X, Cohen C, Zhong H, Kilroy S, Louis G, Moses M and Arbiser JL: Malignant transformation of melanocytes to melanoma by constitutive activation of mitogen-activated protein kinase kinase (MAPKK) signaling. J Biol Chem 278: 9790-9795, 2003.

15. Yanase H, Ando H, Horikawa M, Watanabe M, Mori $\mathrm{T}$ and Matsuda N: Possible involvement of ERK 1/2 in UVA-induced melanogenesis in cultured normal human epidermal melanocytes. Pigment Cell Res 14: 103-109, 2001.

16. Hata K, Hori K and Takahashi S: Role of p38 MAPK in lupeol-induced B16 2F2 mouse melanoma cell differentiation. J Biochem 134: 441-445, 2003.

17. Ali SA, Sultan T, Galgut JM, Sharma R, Meitei KV and Ali AS: In vitro responses of fish melanophores to lyophilized extracts of Psoralea corylifolia seeds and pure psoralen. Pharm Biol 49: 422-427, 2011. 